\title{
Creating Spaces for the Development of Critical Awareness through Literature: The Methodological Anatomy of Literary Texts in English
}

\author{
Yolanda Caballero Aceituno \\ University of Jaén, Faculty of Humanities and Social Sciences \\ Department of English Philology \\ Campus Las Lagunillas, s/n, Jaén 23071, Spain \\ Tel: 34-953-212-608Ｅ-mail: ycaballe@ujaen.es
}

Received: November 22, 2011

Accepted: November 28, 2011

Published: December 1, 2011

doi:10.5539/ies.v4n5p10

URL: http://dx.doi.org/10.5539/ies.v4n5p10

\begin{abstract}
Most students of the joint degree in English Philology and Tourism, taught at the University of Jaén (Spain), usually complain about the fact that the teaching of literature is sometimes reduced to the theoretical study of literary periods and bio-bibliographical data about authors. This approach overlooks one of the main functions of literary texts: their contribution to the definition of our students' ideological positioning in the world. Raising critical awareness through literature is, without any doubt, one of the principles that should guide the design of every literary syllabus. The teaching programme of the compulsory subject Textos Literarios en Lengua Inglesa (Literary Texts in English) revolves around this belief. This subject has been structured around the analysis of several literary texts by authors from different periods which examine key cross-curricular issues such as ideological independence, alienation, authenticity or multicultural awareness. The traditional stylistic analysis of literary texts has been complemented with the inclusion of strategies to foster the students' capability to express their critical opinion and establish meaningful connections between the message of a text and their own lives. The aim of this paper is to discuss the methodological anatomy of these strategies.
\end{abstract}

Keywords: Critical awareness, Creative capability, Ideological independence, Translatability, Humanistic usefulness of literature, Semiotic theory of culture, Reader-response approach, Stylistic practice for critical awareness.

\section{Literature, Life and Critical Awareness: The Meaningful Link}

The aim of this paper is not to present any exhaustive theoretical framework about how to raise the students' critical awareness through literature in the EFL classroom. Rather, we intend to share, on the one hand, the methodology implemented in our lessons and, on the other, to discuss some practical activities orientated towards achieving this aim, which have resulted in what could be described as a fruitful teaching experience. Thus, the anatomy of the process by means of which a classroom environment prone to the development of critical thinking has been created will be clarified.

In the eighteenth century, the writer Laurence Sterne (1713-1768) warned readers that "much reading" meant "much knowledge" and encouraged the "unlearned reader" to "read, read, read, read" (Tristram Shandy III. xxxvi, pp.203-204), so that they could be ideologically independent. Three centuries have passed and one of the most important documents regulating the adaptation of the degrees of our University to the requirements of the European Higher Education Area (Libro Blanco de la ANECA para el título de grado en estudios en el ámbito de la lengua, la literatura, la cultura y la civilización) still claims that two important interrelated competences, namely, "la capacidad para el razonamiento crítico" [the capability for critical reasoning] and "la capacidad creativa" [the creative capability] (ANECA, 2005, p.295) should be embedded within the study of English Literature.

The training in these basic competences has sometimes been obscured by an excessive emphasis on approaching literature as a compilation of biographical data about authors and the literary periods to which they belong to be learned (when not memorized). It must also be argued that literary texts have been frequently exploited by giving students pre-conceived theories or topics for analysis. In a very interesting book entitled $A$ Call for Cultural Symbiosis (2005), Jüri Talvet has also argued: 
Teaching literature and arts at schools and universities involves a special responsibility for the formation of a young human being. In this practice, too, we observe a prevailing one-sidedness. On the one hand, professors appear as technicians whose exclusive interest is the form and the structure of a work of art. They are capable of an admirable scrutiny and vivisection of formal details, they indulge in all kinds of 'scientific' schemes and formulae when explaining their object, but what they say about its philosophical or ideological content is mostly reduced to an astonishing banality. (2005, pp.86-87)

On many occasions, a true dialogue between the student as reader and the unbounded potential of the literary text has not been favoured. Very frequently, we do not speak to our students, for example, about the beneficial influence of literature from a humanistic point of view, which has become what could be termed a hidden curriculum. To compensate for these deficiencies, it is absolutely necessary to show our students how literature offers a special access to the understanding of the world which is permeated by a sensibility missing in other academic disciplines. Quoting the words that Jüri Talvet has used in a different context, it could be argued that literature "[...] makes us its signs, and provides us with a capacity to intuit its other signs, to dialogue with them and, thus, be orientated in our temporal lives, as well as to survive our existence with a certain dignity" (2004, p.151). In On Literature (2002), John Hillis Miller also inserted some thought-provoking reflections about the essence of literature. He argued that "a literary work is not, as many people may assume, an imitation in words of some pre-existing reality but, on the contrary, it is the creation or discovery of a new, supplementary world. [...] This new world is an irreplaceable addition to the already existing one" (2002, p.18).

Apart from creating new worlds -the exploration of which will enrich our worldview- literary works bring about some changes which transcend the space of fictionality and affect real life. As Hillis Miller claims, literature is, above all, "performative utterance [...] a way of doing things with words. It does not name a state of affairs, but brings about the thing it names" (2002, p.37). In this respect, three decades ago Edward Bond also claimed that "art is the imagination of the real and not the invention of fantasy"; that is to say, "art helps to create meaning and purpose in what is in many ways an apparently irrational world" (1976, pp.xv-xvi). However, as Jüri Talvet has noted, the notion that "literature and arts cannot improve life directly, in the material and economic sense" (2005, p.90) currently enjoys a great popularity: "Science has become clearly an ally of economic power structures and, supported mightily by the latter, has become an overwhelming new religion [...] menacing humanities and arts—all that in which the spiritual germ still resides" (Talvet, 2005, p.80).

With Talvet, we agree, though, that literature and the arts are productive vehicles for activating critical awareness and conducting "a rebellion against the reason-governed power-mechanisms". Although their "curing effect, $[\ldots]$ in contrast with the effects of medicine, [is] invisible" (2005, pp.25, 11),

$[\mathrm{L}]$ iterature and art are always psychologically and spiritually practical, and sometimes socially, too, although the latter is most likely to occur in an indirect way: by psychologically and spiritually influencing individuals who compose society. There is something definitely primitive in the way of thinking of those intellectuals who deny the social role of literature and arts. They themselves tend to think in a business-like way: they would like to see the effects in a week. If the effect is not produced in a week, they conclude that it does not exist. (Talvet, 2005, p.89)

Our teaching practice is permeated by this belief in the humanistic usefulness of literature. The literary text is not something aseptic, disconnected from what we do and feel as human beings. Literature really affects us in a positive way. In his second edition of Tristram Shandy, Laurence Sterne incorporated a dedication addressed to William Pitt the Elder (1708-1778) which reveals this ideal. Apart from defining his book as a "Fragment of Life" (Tristram Shandy, p.3), he asked Pitt to "honour this book by taking it-—(not under your Protection,_- it must protect itself, but)_-into the country with you [...]" (p.3). The dedication clearly indicates that Tristram Shandy was not designed as an aseptic piece of writing, separated from its readers' lives. By asking William Pitt to take the book "into the country" with him, Sterne is metaphorically asking him to see the book as an inseparable accompaniment of his life.

These words by Sterne truly encapsulate how we want our students to see literature: as a meaningful part of their lives. This principle has permeated the course planning of the subject Literary Texts in English. The results of the questionnaires administered to the students that evaluate our teaching performance have been motivating. But we would only consider this experience successful taking into account other results: those materialised in the critical essays that the students had to submit at the end of each semester. Their content shows that our students have been capable of revisiting literary texts in a new light, using them to raise thought-provoking questions that directly address the relationship between literature and life. 


\section{Methodological Principles to Develop Critical Awareness: Some Examples}

The methodological paradigms guiding our teaching practice will be contextualized within Literary Texts in English, a fourth-year compulsory subject belonging to the joint degree in English Philology and Tourism taught at the University of Jaén (Spain). When coming to teach this subject, we found that the students brought with them a rich background which was ready to be exploited in order to train them in the exercise of critical consciousness. As we have previously noted, this is a fourth-year subject, which means that learners have already studied English Literature I, II and III and are simultaneously studying English Literature IV. When they come to Literary Texts in English they are equipped with a sound or, at least, acceptable knowledge of authors, literary periods, literary schools and theories, and also, of stylistics and discourse analysis. Apart from having had the chance to exploit this background, we have enjoyed a great privilege. According to the official regulations, the descriptor for this subject is, simply, the selection and analysis of literary works, so we have freely designed the syllabus of this subject without having had to subject to the tyranny of circumscribing our students' experiences with literature to a given period or a specific set of authors. Taking into account the two aforementioned variables (the students' rich background and our freedom to design the syllabus), we followed some very simple programmatic and methodological principles to create the conditions that could foster the development of critical awareness.

The first principle (more programmatic than methodological) has to do with an essential belief: exploiting the potential of the literary text requires a stress-free environment. It is true that reading for pleasure becomes a utopia when students have to subject to a tight schedule and are bound to analyse texts with an evaluative task in mind, but we can still make an effort to create a more relaxing atmosphere. The fourth year of the degree in English Philology and Tourism is a quite stressful period for our students, who are about to graduate. As our main objective was to make them feel that literature is a special accompaniment of their lives -i.e. to train them to identify meaningful links between the message of the literary text and their feelings and ideology- we decided not to select overly long readings because they would not have enough time to read, let alone to critically reflect upon the messages communicated by the texts. From our point of view, the subjects devoted to literature must never be a source of stress: working with literary texts must be a therapeutic activity, capable of encouraging autonomous reading habits outside the classroom. This is the reason why, when programming the subject, we chose to focus on ten short stories:

i. “An Outpost of Progress” (1896), by Joseph Conrad.

ii. “The Dead" (1907), by James Joyce.

iii. "Bliss" (1920), by Katherine Mansfield.

iv. "The Rich boy" (1926), by F. Scott Fitzgerald.

v. “To Room Nineteen" (1963), by Doris Lessing.

vi. "Everyday Use" (1973), by Alice Walker.

vii. "A Family Supper" (1982), by Kazuo Ishiguro.

viii. "Converging City" (1986), by Ben Okri.

ix. Selected fragments from The House on Mango Street (1984), by Sandra Cisneros.

x. "The Jack Randa Hotel” (1994), by Alice Munro.

From the list above, it can be deduced that our second programmatic principle had to do with the Bakhtinian ideal of polyphony. We truly believe that, to feel attracted towards literature, students need to get the impression that it is a vehicle for exploring the richness and diversity of the world. From a thematic point of view, the readings gave them the chance to get immersed in both female and male worldviews, in the center and the periphery, in everyday issues or fantastic re-constructions of reality. The presence of controversial topics -such as alienation, social differences, the loss of identity or the clash between different cultures- was highlighted so as to minimize indifference. The readings were also referred to a wide geographical area (from England to Nigeria) so that students could see how and why literature is used in many different contexts, because its purpose is never neutral. The message of the literary text may, for example, be compatible with its context of culture, but may also subvert its sometimes alienating normalities, opening new horizons of possibility.

Taking into account the aforementioned programmatic principles, the most important methodological axis in order to facilitate the establishment of meaningful links between literature and life (the basis for the development of critical thinking) is, in Gonçalves Matos' words, to "[...] work within a reader-response framework", because "as the reader participates in making the text real, s/he lives through the texts, finds a voice through them and moves towards appropriation of the text" $(2005$, pp.62, 68). In order to clarify how we worked in our lessons to create this 
framework, some references to Jüri M. Lotman's semiotic theory of culture must be included. Our literature classroom could be considered one of the spaces for generation of meaning within the semiosphere, (Note 1) one of its micro-representations, mimicking its general working mechanisms. Lotman, who used this concept to explain the relations between different cultures, argued that every cultural semiosphere has a "territorial character" (2005, p.211), as it is bordered by an abstract frontier that separates it from other cultures which, before a fruitful process of dialogue and incorporation, can be initially perceived as "extra-semiotic" reality (2005, p.208): "The boundary can be defined as the outer limit of a first-person pronoun. This space is 'ours', 'my own', it is 'cultured', 'safe', 'harmoniously organized', and so on. By contrast, 'their space' is 'other', 'hostile', 'dangerous', 'chaotic'” (2001, p.131).

Applying Lotman's ideas to our context, it could be argued that the "harmoniously organized space" he mentions can be metaphorically connected with the realm of known responses to the literary text -for example, the messages validated by critical scholarship that our students have to study- whereas the other realm could be connected with those unexpected responses originated in the students' uniquely personalized dialogue with the text (the result of which, unfortunately, could be described in some teaching contexts as "chaotic" or "extra-semiotic"). Our teaching practice must, by contrast, validate their responses within the classroom and, using Hillis Miller's terms, make our students perceive them as "irreplaceable additions to the already existing one[s]" (2002, p.18). As Jüri Talvet has argued:

It would be totally inadmissible to ignore the formal experiments by which the great psychological novelty of the work of James Joyce, Virginia Woolf or William Faulkner was achieved. However, it would be equally misguided to try to make these formal innovations a dogma and an absolute criterion in evaluating a work of art. $(2005$, p. 84$)$

Lotman also describes the boundary as '[...] a mechanism for translating texts of an alien semiotics into 'our' language", as "the place where what is 'external' is transformed into what is 'internal"' (2001, p.136). We want our students to be frontier students, and work in that productive space that separates the external (i.e., the plot of the texts themselves, still unprocessed by our students' creative minds; the socio-cultural, historical or political circumstances under which texts were written; the biographical data or the author's vital experiences that might have influenced their content; the existing critical scholarship, etc.) from the internal (the students' thoughts, feelings, ideas and personal circumstances, which will guide their individualised appropriation of the text). As Lotman claims, the boundary is "the hottest spot [...] for semioticizing processes", "a place of incessant dialogue" (2001, pp.136, 142) where, by exercising critical thinking abilities, our students can exploit their background knowledge to discover in the text messages that are meaningfully related to their positioning in the world as human beings. The boundary is, thus, a highly productive symbiotic locus.

We must facilitate our students' access to all the aforementioned external information by encouraging them to refresh their previous literary background, revitalizing and problematizing it and, wherever possible, creating personalized study guides for every short story analyzed under our supervision. However, fostering the students' internal dialogue with the text is equally important and also requires guidance on the part of the teacher. From the point of view of content, an essential principle to be followed is to make our students move beyond the analysis of the plot of the short story and work as archaeologists looking for the vital philosophy or teleology hidden behind the surface of sequential narrative events. As Talvet has noted, literary works are "[...] creative acts which, despite all individualities, share a certain basic unity of human attitudes or, philosophy" $(2004$, p.142). In this respect, working thematically is advisable. Working thematically promotes the translatability of the text (i.e., enables the students to take the message of the text into their own lives and make it meaningfully functional within them) and consists in creating zones for the students' experiential and emotional identification with the characters, the authors or the content of the texts. The human must complement -and even overpower- the academic when working with literature. In spite of the temporal, cultural or geographical distances, most stories are articulated around timeless issues that recreate human feelings and dilemmas with which our students can easily feel identified. Discovering them, and articulating the analysis of both the content and the style of the short stories around these central topics to see how they are encoded and communicated, is an intellectually demanding activity which may spark our students' critical awareness.

A meaningful thematic area to activate critical thinking can be created by, for example, exploiting a topic which is intimately connected with this issue: freedom and ideological independence. At a surface level, "An Outpost of Progress", by Joseph Conrad, recreates the story of two white men (Kayerts and Carlier) who dream of becoming "pioneers of trade and progress" (Conrad, 1967, p.62) in Africa but are unsuccessful in a colonialist civilizing mission, which eventually causes their death. At the deeper level we want our students to critically explore, Kayerts and Carlier are just two timeless pretexts, two vehicles for communicating how human beings can easily lose the 
essentiality of their inner selves when they are isolated in an alien and defamiliarizing environment, far away from a civilized society that had "forbidd[en] them all independent thought, all initiative, all departure from routine" (Conrad, 1967, p.60). In Katherine Mansfield's "Bliss", the focus is not on Bertha Young (a somehow subversive mother and wife who feels attracted towards other women) or on her adulterous husband, but on the passionate conflict between her alienated state (caused by her subjection to the behavioural and materialistic superficialities of middle-upper classes) and her emergent (but consciously unacknowledged) dreams of unbounded self-realization, dialogically voiced in internal monologues such as the one below:

Really-really-she had everything. She was young. Harry and she were as much in love as ever, and they got on together splendidly and were really good pals. She had an adorable baby. They didn't have to worry about money. They had this absolutely satisfactory house and garden. And friends-modern, thrilling friends, writers and painters and poets or people keen on social questions-just the kind of friends they wanted. And then there were books, and there was music, and she had found a wonderful little dressmaker, and they were going abroad in the summer, and their new cook made the most superb omelettes...

"I'm absurd. Absurd!” She sat up; but she felt quite dizzy, quite drunk. It must have been the spring.

Yes, it was the spring [...] (Mansfield, 2001, pp.96-97)

Bertha's conflict is the same that kills Susan Rawlings, the main character of Doris Lessing's "To Room 19". When Susan goes to her garden and sees "some sort of demon" (Lessing, 1988, p.163), she is not describing the vision of a neurotic woman: she is confronting her destabilizing thoughts, the voice of her authentic inner self rebelling against a too perfectly organized and planned existence revolving around a "big house, on which the mortgage still cost four hundred a year, a husband, so good and kind and insightful; four children, all doing so nicely; and the garden where she sat; and Mrs Parkers, the cleaning woman" (Lessing, 1988, p.160), elements that can no longer make her happy. In "The Dead", by James Joyce, Gabriel Conroy also discovers that the social superego can corrupt and overpower his purest inner self, which all through the short story is metaphorically buried under the snow of social masks, a snow " [...] falling faintly through the universe and faintly falling, like the descent of their last end, upon all the living and the dead" (Joyce, 1967, p.200). Bertha, Gabriel and Susan (who lead different lives and belong to different cultural contexts) exemplify the negative consequences of living up to others' expectations, a very common human situation which might allow our students to see themselves contained in it.

Apart from working thematically, a stylistic analysis aimed at activating critical consciousness must be inserted in the EFL classroom. The special use of language that characterizes literary texts is, on the one hand, the sensory vehicle for turning static graphemes into powerfully signifying elements and, on the other, for facilitating the students' emotional and experiential appropriation of the text. In order to raise critical awareness, it is necessary to move beyond the coldness of structuralist parameters and lead our students to discover that even the (seemingly) most insignificant linguistic items are permeated by feelings and ideology. If, from the point of view of content, we invited our students to organize the analysis of literary texts by identifying commonly shared human situations, from a formal point of view, we must encourage them to find out how, from the beginning to the end, the use of language in the literary text is highly intentional. The word beginning is being used here literally: the analysis of titles (very frequently overlooked) leads us to discover the whole philosophy behind the composition of the selected short stories: "An Outpost of Progress" conceals the biggest irony in the story, as there is no progress, but regression. The same as there is no happiness in "Bliss", and everything but a united family in Kazuo Ishiguro's "A Family Supper". Likewise, "The Dead" invites us to critically re-examine who the dead are: surprisingly, not the people who passed away and are constantly alluded to in a story permeated by melancholy, but those who are attending a party.

Another necessary ingredient to activate critical thinking when conducting a stylistic analysis is to lead students to discover how literature operates alchemical transformations by, for example, turning prosaic everyday objects into powerful symbols. In "An Outpost of Progress", a violent argument over a simple lump of sugar brings about a tragedy, with Kayerts killing Carlier and committing suicide afterwards. The lump of sugar comes to symbolise the weaknesses of human beings, the loss of our supposedly civilized identities when physical needs take hold of our rationality. It is also necessary to move beyond the surface of the physicality of some elements to highlight their spiritual dimension. As has been previously mentioned, the snow that falls in "The Dead" is not only a natural element, but a metaphor for the social masks that bury the authenticity of our inner selves. Even the description of distances may turn philosophical. Suspended between her house (an oppressive environment where she cannot be herself because she must artificially behave as the perfect mother and wife) and her garden (a minimal space for her unbounded dreams and her freedom), Bertha Young, the main character of "Bliss", likes to contemplate "a tall, slender pear tree in fullest, richest bloom" which she explicitly defines as "a symbol of her own life" (Mansfield, 2001, p.96), of her latent youth, her spontaneity and her enthusiasm for life. The significant fact is that the pear tree 
is placed "at the far end" of the garden (Mansfield, 2001, p.96). The adverb far symbolically indicates that happiness and self-fulfilment are far from an alienated Bertha trapped in a world of enforced composure. Small details such as far are more eloquent than many paragraphs. In "A Family Supper", the father of the narrator is a man "proud of [his] pure samurai blood" (Ishiguro, 1988, p.435) who tries to keep his family united in Japan to prevent the contamination of their traditional Japanese life-style with the pernicious influence of other cultures. However, the son has experienced California, and the daughter, Kikuko, also dreams of going to America. Although the story is permeated by suspense and overtly open-ended, one possible interpretation is that the father has prepared a family supper by cooking a poisonous fish ( $f u g u)$ to kill them all and, in this way, stop the unwanted dismemberment of his family. When, in the course of a conversation permeated by coldness and awkward silences, the son asks the father whether he "will [...] go into business again", he coldly answers: "I am-in retirement" (Ishiguro, 1988, p.435). The dash has not been inserted to merely indicate a speech pause, but to graphically transport us to other spheres of signification. This apparently naïve detail contributes to emphasizing the irony contained in the word retirement, which may connote the definitiveness of death, thus acting as a powerful anticipatory element.

Within the framework of a stylistic practice aimed at enhancing critical awareness, the analysis of the philosophical eloquence of linguistic elements must be complemented with the exploration of the sensorial environment that they create and the enjoyment of the lyricism they impart. As Talvet has argued, writers communicate a philosophy "[...] which is not only understood, but felt, i.e., received not only by the intellect but the senses and the intellect closely knit together" (2004, p.141). The juxtaposition of the "dusky" and "chilly" atmosphere of Bertha Young's dining room and "the tangerines and apples stained with strawberry pink [...] she had bought to tone in with the new dining room" (Mansfield, 2001, p.92) purposely captures our senses and suggests that a significant message is hidden under the cover of so many powerfully evocative references to colours and smells: Bertha is trying to bring her cold house alive and, by extension, to introduce a dissonant element in her alienating normalities, to rewrite her mediocre existence as something positive.

In connection with this appeal to our senses (which, without any doubt, settles the basis for the students' emotional appropriation of the text), the potential of suggestive images must also be exploited. We must show our students that, sometimes, images are imperialistic and can epitomize the whole message of the text. As it was the case with "An Outpost of Progress", the title of Scott Fitzgerald's "The Rich Boy" is potentially ironic. Anson Hunter, the main character, is "the eldest of six children who would some day divide a fortune of fifteen million dollars" (Fitzgerald, 1969, p.320). Fitzgerald lets us know that "upper-class men who passed him on the street knew without being told that he was a rich boy and had gone to one of the best schools" $(1969$, p.321). However, he has not been educated to feel real affection for anybody. He tries to soften the emptiness his life is progressively turning into by going to parties and drinking heavily, but is unable to admit that his existence has exclusively revolved around dissipation, being thus condemned to loneliness. The close-up of his encounter with a stranger in a club anticipates the destiny he is reluctant to confront and visually verbalises what the end of the story does not show: "From the broad window of one of his clubs-one that he had scarcely visited in five years-a grey man with watery eyes stared down at him. Anson looked quickly away-that figure sitting in vacant resignation, in supercilious solitude, depressed him" (Fitzgerald, 1969, p.349).

A practice of discourse analysis guided by the principle of strengthening the indissoluble link between literature and life must also focus our students' attention on those key paragraphs that, out of their generic quality, encapsulate universal feelings and thoughts that deconstruct the distance between the readers and the message of the text. These elements can be considered easily transportable into our students' lives, and are likely to be stored in their memories, thus turning the text into a lasting accompaniment of their vital experiences and a contributor to the configuration of the texture of their worldviews. For example, when reading and analysing "An Outpost of Progress", we drew the students' attention towards the translatable potential of memorable philosophical maxims such as the one cited below:

Few men realize that their life, the very essence of their character, their capabilities and their audacities, are only the expression of their belief in the safety of their surroundings. The courage, the composure, the confidence; the emotions and principles; every great and every insignificant thought belongs not to the individual, but to the crowd: to the crowd that believes blindly in the irresistible force of its institutions and of its morals, in the power of its police and of its opinion. But the contact with pure unmitigated savagery, with primitive nature and primitive man, brings sudden and profound trouble into the heart. To the sentiment of being alone of one's kind, to the clear perception of the loneliness of one's thoughts, of one's sensations, to the negation of the habitual, which is safe, there is added the affirmation of the unusual, which is dangerous; a suggestion of things vague, uncontrollable, and repulsive, whose discomposing 
intrusion excites the imagination and tries the civilized nerves of the foolish and the wise alike. (Conrad, 1967, pp.58-59)

Conrad's reflections transcend the microcosm of Kayerts and Carliers' existence and address a macrocosmic problem: the lack of individual ideological independence, the undesirable state which we timidly intend to overcome in our literature lessons by activating critical thinking.

\section{The Final Movement: From Identification to the Critical Verbalization of the Process of Appropriation}

Once we have created zones for the students' emotional and experiential identification with the message of the literary text and favoured their attachment to it by emphasizing the magic of the linguistic medium by means of which thoughts and passions are encoded, the most suitable conditions to let students generate and verbalize new responses to the text - which go beyond "petrified significations" (Talvet, 2004, p.140) - will have been created. Jüri M. Lotman argues that

a text, like a grain of wheat which contains within itself the programme of its future development, is not something given once and for all and never changing. The inner and as yet unfinalised determinacy of its structure provides a reservoir of dynamism when influenced by contacts with new contexts. (2001, p.19)

The existence of this "reservoir of dynamism" opens up the text towards infinite possibilities of exploration and appropriation of its message. In our view, the most vivifying expansions on the inextinguishable semiotic potential of the literary text will be those emanating from highly personalized responses to the text which complement those already known. This belief justifies a teaching practice based on activating our students' critical awareness. As has already been mentioned, the production of these highly personalized responses requires working thematically and aesthetically towards creating possible areas of identification between the world of the reader and the world of the text, and it is precisely in our students' ability to describe how the transference of the text into their inner selves has taken place that new insights into its potential are generated. The students' description of this process of transference in their critical commentaries may be positive: they may have found the message of the text specially related to their feelings and thoughts as human beings. It may also be negative when no meaningful connections between the text and their personal situation are identified. However, whatever the result may be, deepening into the essence of a literary text entails exploring the otherness of a different world, and this intense symbiotic contact between the external and the internal will certainly make our students intellectually richer and by, extension, better human beings, able to verbalize their non-conformism with the dogmatism that, on occasions, tries to rule the destinies of their vital microcosms.

\section{References}

ANECA. (2005). Libro blanco de la ANECA para el título de grado en estudios en el ámbito de la lengua, la literatura, la cultura y la civilización. Madrid: Agencia Nacional de la Evaluación de la Calidad y Acreditación.

Bond, E. (1976). The fool \& We come to the river. London: Methuen.

Conrad, J. (1967). An outpost of progress. In C. Dolley (Ed.). The penguin book of English short stories. London: Penguin. pp. 56-82

Fitzgerald, S. F. (1969). The rich boy. In J. Cochrane (Ed.). The penguin book of American short stories. London: Penguin. pp. 319-357

Gonçalves Matos, A. (2005). Literary Texts: A Passage to Intercultural Reading in Foreign Language Education. Language and Intercultural Communication, 5 (1), 57-71. http://dx.doi.org/10.1080/14708470508668883

Hillis Miller, J. (2002). On literature. London: Routledge.

Ishiguro, K. (1988). A family supper. In M. Bradbury (Ed.). The penguin book of modern British short stories. London: Penguin. pp. 389-400

Joyce, J. (1967). The dead. In C. Dolley (Ed.). The penguin book of English short stories. London: Penguin. pp. 157-200

Lessing, D. (1988). To room nineteen. In M. Bradbury (Ed.). The penguin book of modern British short stories. London: Penguin. pp. 150-180

Lotman, J. M. (2001). Universe of the mind: A semiotic theory of culture. Trans. A. Shukman. London \& New York: I. B. Tauris.

Lotman, J. M. (2005). On the Semiosphere. Trans. W. Clark. Sign System Studies, 33 (1), 205-229.

Mansfield, K. (2001). Bliss. In Katherine Mansfield: The collected stories. London: Penguin. pp. 91-106 
Sterne, L. (2003). The life and opinions of Tristram Shandy, gentleman (The Florida Edition). Eds. M. New and J. New. London: Penguin.

Talvet, J. (2004). Between dreams and reality: The message and the image of Renaissance humanism. In L. García García et al. (Eds.). Sederi XIV: Yearbook of the Spanish and Portuguese society for English Renaissance studies (pp. 137-152). Jaén: Servicio de publicaciones de la Universidad de Jaén.

Talvet, J. (2005). A call for cultural symbiosis: Meditations from U. Trans. H. L. Hix. Toronto: Guernica.

\section{Note}

Note 1. Lotman defined the semiosphere as "the whole semiotic space of the culture in question. [...] The semiosphere is the result and the condition for the development of culture. [...] We justify our term by analogy with the biosphere [...] namely the totality and the organic whole of living matter and also the condition for the continuation of life" (2001, p. 125). 